\title{
Greenhouse Wireless Network Monitoring and Management Using IoT
}

\author{
Tejaswita Jagdale ${ }^{1}$, Dr. M.B. Mali ${ }^{2}$ \\ Student, Dept. of Electronics \& Telecommunication, Sinhgad college of Engg., Vadgaon (Bk.), Maharashtra, India. ${ }^{1}$ \\ HOD, Dept. of Electronics \& Telecommunication, Sinhgad college of Engg., Vadgaon (Bk.), Maharashtra, India. ${ }^{2}$
}

\begin{abstract}
Indian agriculture is the major private sector enterprise in the country so the India's economic security depends on agriculture sector as of now and in near future. Monitoring and control of greenhouse environment plays an important role in crop production and this may results in maximum photosynthetic activity. This project consists of design and implementation of a Wireless Sensor Network that can monitor the temperature, humidity, soil moisture, incident light intensity in the greenhouse filed area. So farmers can recognize the environmental conditions and implement various methods to increase the greenhouse crop production. The system is integrated with particular sensors, Microcontroller and radio frequency modules forms sensor node. All monitored parameters that sensed by various sensors are transmitted through a wireless RF link XBee to MCU which is acting coordinator node and designed to take corrective action once exceed the threshold parameters. There is interface between MCU and PC so the data at MCU can be maintained in VB for further process. As well as interface between PC to GPRS shield for internet connectivity to avail IoT. By using Internet of things the data can be access from anywhere and this is most advantageous among the existing greenhouse system.
\end{abstract}

Keywords: MCU, IoT, WSN, RF module.

\section{INTRODUCTION}

Automated greenhouse is the key of modern agriculture. In this article, automated agricultural model based on Agricultural service function growing now a days and Internet of things designed and implemented with real informationization adds on the value in agricultural time monitoring and management of greenhouse sustainable growth. Traditional agricultural development parameters.

cant fulfilled the present requirements of agricultural sustainable growth. For changing the traditional mode of the agricultural automation this system introduces the application of internet of things in greenhouse automation which can reduce the manpower. So with the function of automated intelligent remote controlling of the greenhouse obtained real time and accurate crop environment information.

The system contains sensor network that includes various application specific sensors, computer network, information network and satellite network that forms a huge network [1].This can satisfy the need of advanced automated agricultural production with the help of sensor node which collects environmental parameters, wireless module that transmits parameters and forms transmission network, VB database module that stores information in database, GPRS module that introduces internet connectivity so as to put data on internet and forms satellite network to avail data from anywhere.

The information gathered in database and threshold value automatic remote controlling take place. As Per Congcong. Li et al, Internet of things are widely used in China [1]. There are various agricultural irrigation farming implementing methods. Azzatdin A. A. uses GSM short message technology to understand real time controlling of greenhouse [2]. Imaran B. Z. implemented wireless monitoring system using nRF24L01 and database using Microsoft visual studio [3]. Abhfeeth K. A. used monitoring database with LABVIEW platform.

\section{EXPERIMENTAL SET UP}

The requirements in real-time, reliability and sustainability should be meet for crop-growth for this the intelligent system is designed. In this system, a wireless sensor network with software was designed and implemented for the Greenhouse wireless sensor network monitoring and Management in order to achieve intelligent controlling of greenhouse crops growing environment. It can sense important environmental parameters like Temperature, Humidity, Soil moisture, Light intensity for plants in real time with the help of sensors and microcontroller. It transmits sensors information wirelessly with the help of RF link i.e. XBee to central location for further analysis. The environmental parameters like Sunlight, Temperature, Humidity and soil moisture are controlled by the whole system. The sensing network runs by AVR microcontroller ATmega328P which is based on Arduino UNO Module. For communication purpose, a RF link $2.4 \mathrm{GHz}$ ISM band Transmitter-Receiver installed to transmit or receive these information to $\mathrm{PC}$ which is located at central location as well as to GPRS module for internet accessibility and to cloud for further analysis.

To design hardware for green house monitoring various sensors are used to control the environment. The parameters like greenhouse temperature, humidity, light intensity for green house and soil wetness for crop growth. The green House monitoring system consists of sensor receiver and transmitter Module, and a required power circuits, AVR microcontroller, Signal conditioning circuit, 
supply unit. The outputs of the sensors are given as input GPRS module which is making use of IoT. It also sends to the micro controller to control and update the landlord. API keys for link up the connection to specific channel. In Any parameter changing with set parameter for green this way the data will be uploaded to the server and house systems, the microcontroller will read and stores maintain in servers database. At the same time the from time to time in PC which is interfaced to the Zigbee measured parameters from greenhouse field area can be module. This stores the database for future use. It has shown at PC in the VB form database. divided into two parts.

\section{A. Sensor Node}

As shown in fig.1 various sensors are placed at actual greenhouse field. These sensors are connected in Wireless Sensor Network i.e. a lot of sensor nodes are distributed in the greenhouse area and can make up network. It can sense the changes of the measured physical quantity and give output of the corresponding information change. It should transfer this information to remote central location so the data which is collected from the sensors are given to AVR Microcontroller Atmega 328P. This Microcontroller is connected to the RF module i.e. XBee S2 which is Transceiver and it sends data wirelessly to central unit. This whole combination of block acts as a slave.

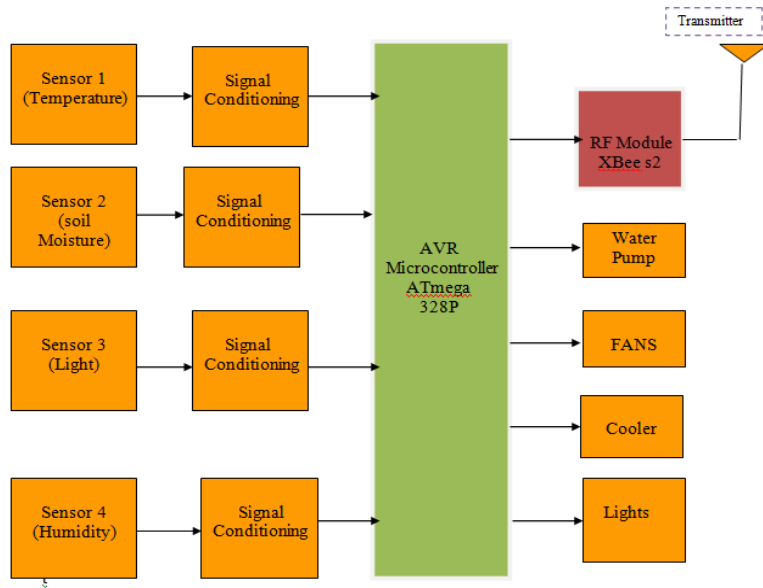

Fig. 1 Block diagram of Sensor Node

\section{B. Coordinator Node}

Fig. 2 shows the co-coordinator node. It is consisting of the XBee transreceiver which gets the data and decode it. The Microcontroller Atmega 328P which is acting as Master controller processes the data and makes packet of the parameters values. It also applies IP Header and authentication key to the packets. Then with the help of AT commands microcontroller Atmega 328P communicates with SIM900 GPRS module. This will initialize the internet connection.

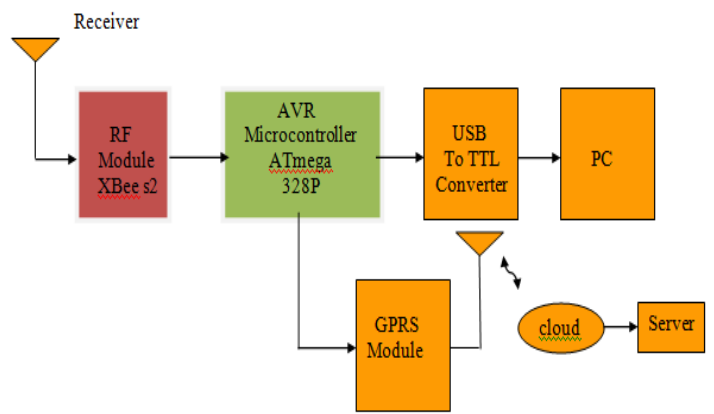

Fig. 2 Block diagram of Coordinator Node

After successful connection, the microcontroller sends HTTP post commands to thing speak server via SIM900

\section{III.VB DATABASE MANAGEMENT}

The information about environment and crop condition in real time is collected from the coordinator node and stored in database of the computer through RS232 interface. So it can check anytime. This database designed by VB and the results are shown in fig. 3

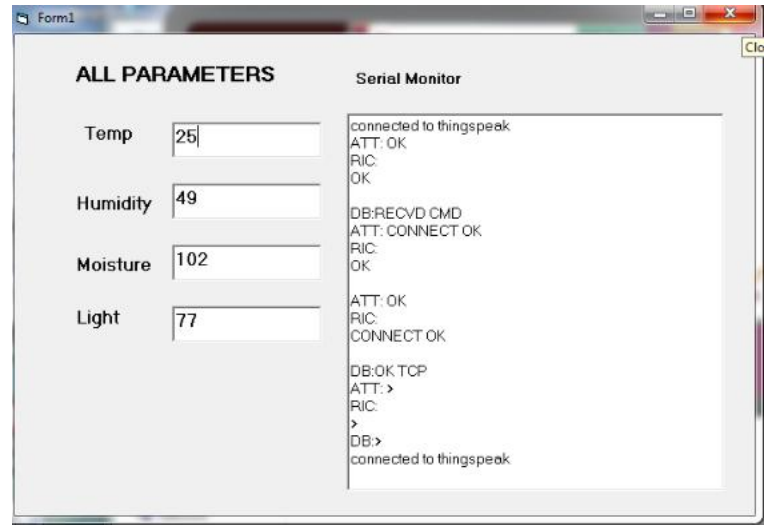

Fig. 3 Sensor parameters in VB database

Fig. 3 shows the real time parameters that are sensed at actual field area of the greenhouse in particular field of the database form. These values get updated time to time once parameters changed according to current environment of the greenhouse. The interface of VB is provided to the IoT with the help of thingspeak website.

\section{IV.INTERNET OF THINGS}

The Internet of Things (IoT) is the network of physical object, parameters or things embedded with electronic, sensors and network connectivity. This enables object to collect data remotely as well as facility to exchange data. The Internet of Things allows objects to be sensed and controlled remotely across existing network infrastructure. It can have direct combination between the physical world and computer-based systems, and resulting in enhanced efficiency, correctness and financial benefit [5]. When IoT is interfaced with sensors and actuators, the technology becomes more significant in agricultural development. It is having wide variety of application in almost all automation fields like smart grid, smart cities, smart home etc.

\section{A. Thingspeak Platform}

Thingspeak is the open source platform for the internet of the things application and API to store as well as retrieve the data from things using HTTP protocol over the internet. Thingspeak enables the establishment of sensor logging application and social network of things with current status updates [6]. The Internet of Things provides access to a extensive range of embedded devices and web services. It can enable to first collect, visualize, analyse, store and act on data from sensors or actuators with Arduino board. 
INTERNATIONAL JOURNAL OF INNOVATIVE RESEARCH IN ELECTRICAL, ELECTRONICS, INSTRUMENTATION AND CONTROL ENGINEERING Vol. 4, Issue 1, January 2016

The most important element of ThingSpeak activity is the channel which contains data fields, location fields, and a status field. After creating a ThingSpeak channel one can write data to the channel, process and view the data. This can be available with tweets and other alerts. The ThingSpeak workflow as follows:

1. Create the channel for particular data and collect data

2. Analysie the data

3. Act on the data

The ThingSpeak includes the complete ThingSpeak API for dealing out HTTP requests, stores alphanumeric data, numeric and processing, location tracking, and status updates[7]. For creating a new channel one needs to sign in and required API key for logging the data.

\section{B. Database on Thingspeak}

The sensor parameters of different field like temperature, Humidity, soil moisture, light intensity are displayed on thingspeak website in real time.
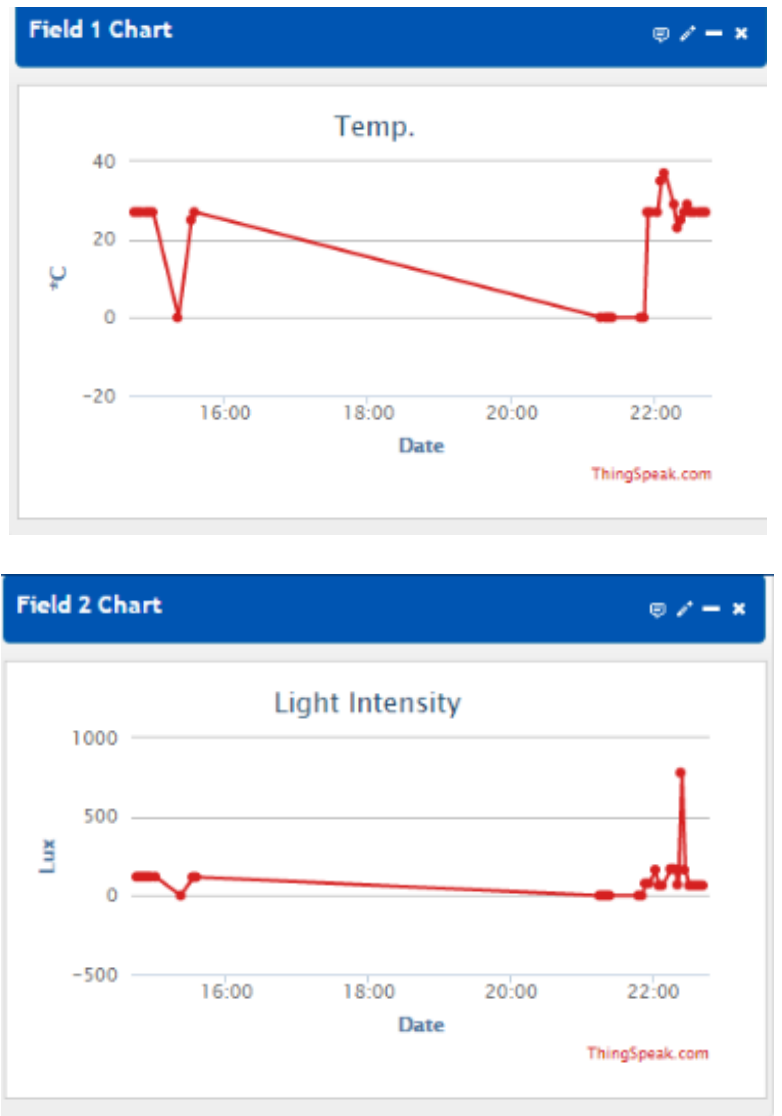

\section{Field 3 Chart}

甲・ーx

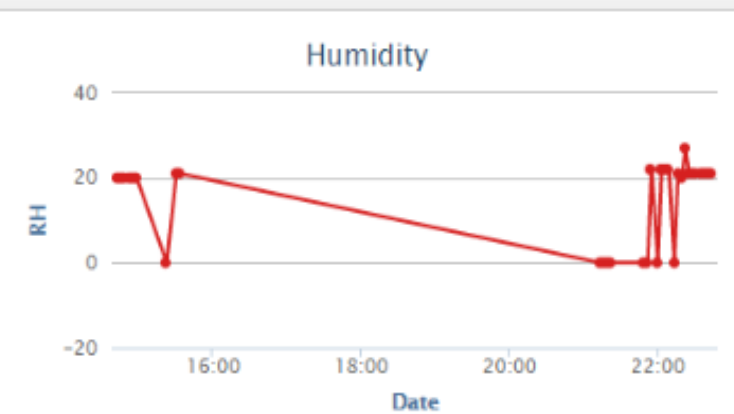

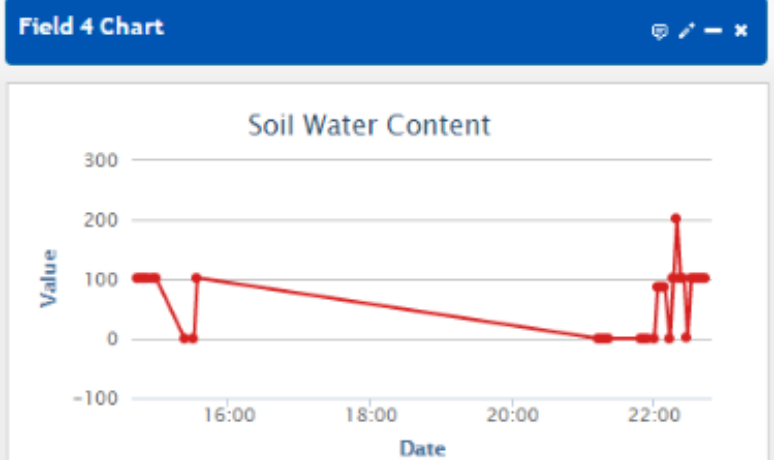

Fig. 4 Field chart of sensor parameters

\section{CONCLUSION}

This work is responsible for information collection, transmission and the agriculture information intelligent processing using Internet of things. One can check the actual greenhouse filed parameter at the base station in VB form as well as can access remotely with the help of thingspeak. Availing the Internet of things in automated agricultural field improves the efficiency of the greenhouses automation, crop production with less manpower and protection of greenhouse environment.

\section{REFERENCES}

[1] Concong Li, Yanxia Guo, "Study and design of agricultural informationization based on internet of things,"Journal of chemical and pharmacitical research,2014,6(6):1625-1630.

[2] Izatdin A.A Haron, "Remote Monitoring in Agricultural Greenhouse Using Wireless Sensor and Short Message Service (SMS)," International Journal of Engineering \& Technology IJET Vol: 9 No: 9

[3] Imran B.J., Kanij R., "Wireless monitoring system and controlling Software for Smart Greenhouse Management," 3rd International conference on informatics, Electronics and Vision 2014.

[4] Abhfeeth K. A, "Wireless sensing and control for precision Greenhouse management,"2012 Sixth International Conference on Sensing Technology (ICST).

[5] https://en.wikipedia.org/wiki/Internet_of_Things.

[6] https://en.wikipedia.org/wiki/ThingSpeak

[7] https://in.mathwork.com/help/thingspeak/getting-started-withthingspeak.html. 